\title{
Phonographic neighbors, not orthographic neighbors, determine word naming latencies
}

\author{
James S. Adelman ANd Gordon D. A. Brown \\ University of Warwick, Coventry, England
}

\begin{abstract}
The orthographic neighborhood size $(N)$ of a word - the number of words that can be formed from that word by replacing one letter with another in its place - has been found to have facilitatory effects in word naming. The orthographic neighborhood hypothesis attributes this facilitation to interactive effects. A phonographic neighborhood hypothesis, in contrast, attributes the effect to lexical print-sound conversion. According to the phonographic neighborhood hypothesis, phonographic neighbors (words differing in one letter and one phoneme, e.g., stove and stone) should facilitate naming, and other orthographic neighbors (e.g., stove and shove) should not. The predictions of these two hypotheses are tested. Unique facilitatory phonographic $N$ effects were found in four sets of word naming mega-study data, along with an absence of facilitatory orthographic $N$ effects. These results implicate print-sound conversion - based on consistent phonology_in neighborhood effects rather than word-letter feedback.
\end{abstract}

The orthographic neighborhood of a word is defined as the set of words that may be formed from it by replacing only one letter with another in the same position. The effect of the size of this neighborhood ( $N$; Coltheart, Davelaar, Jonasson, \& Besner, 1977) on the speed of lexical processing has been examined in many experiments (for reviews, see Andrews, 1997; Mathey, 2001). Andrews (1997) and Mathey (2001) both concluded that large values of orthographic $N$ are associated with fast word naming. Specific evidence of the source of this effect would constrain word recognition models. Some accounts attribute $N$ effects to purely orthographic interactive-activation processes (Andrews, 1989, 1997). In contrast, as will be discussed, several models of word recognition attribute $N$ effects to a print-sound conversion process - orthographic neighbors tend to have similar pronunciations; thus, the effect is not one of orthographic neighbors per se (see Peereman \& Content, 1995, for a discussion of alternative hypotheses and data from French pseudoword and word naming). Evidence for the former interpretation would be difficult to accommodate within current models, since such interactions have little effect on the word level in some (see, e.g., Coltheart, Rastle, Perry, Langdon, \& Ziegler, 2001) or are absent from the model in others (e.g., Plaut, McClelland, Seidenberg, \& Patterson, 1996). In the present article, we tested between the competing explanations of $N$ effects.

When Andrews (1989) first found an effect of orthographic $N$ on word naming for low-frequency words, she interpreted this in terms of the "gang effects" occurring in McClelland and Rumelhart's (1981) interactive-activation (IA) model of visual word recognition, originally used to account for word-superiority effects in the Reicher-Wheeler paradigm (Reicher, 1969; Wheeler, 1970). She argued that processing units for words differing in one letter from the target would receive moderate (spurious) activation in the early stages of word recognition, which would feed back to (mostly) correct letter units, increasing their activation and in turn speeding the recognition of the correct word. Thus, words with many orthographic neighbors would be named faster than those with few. Although Jacobs and Grainger (1992) failed to find such an effect in an IA model, such effects are highly dependent on parameter values and can be found in related models with appropriate parameters (Reynolds \& Besner, 2002). Andrews $(1989,1997)$ has argued that a lexical identification account is most parsimonious, because it may also account for the word-superiority effect as well as a facilitatory effect of orthographic $N$ in lexical decision (Andrews, 1989, 1992, 1997).

However, an alternative account is not only possible but is assumed by many current models. The DRC model of Coltheart et al. (2001) accounts for neighborhood effects by the action of its IA-based lexical route. Coltheart et al. (2001) cited the connections between orthographic word units and phonological word units, and the cascade into phonemes, as causing facilitatory $N$ effects for word and pseudoword naming, although they needed to alter parameter values to find such an effect for words. With this modified parameter set, Reynolds and Besner (2002) have confirmed - using lesion methods - that the effect for words is in fact due to these connections alone; that is, lexical print-sound correspondences bring about effects of orthographic $N$. This explanation, therefore, is not one purely in terms of orthographic identification; rather, it relies upon the orthographic neighbors of a word activating the same phonemes as that word.

Similarly, other computational models of visual word recognition-excepting those that have assumed all-ornothing lexical access - can only account for $N$ effects

J.S.Adelman, j.s.adelman@warwick.ac.uk 
being due to print-sound correspondences. This is because they do not have orthographic word representations; rather, letters are processed immediately into intermediate or phonemic representations. Such models include parallel-distributed processing (PDP) models (see, e.g., Plaut et al., 1996; Seidenberg \& McClelland, 1989; Zorzi, Houghton, \& Butterworth, 1998) and retrieval models (e.g., Kwantes \& Mewhort, 1999). Moreover, PDP models do produce orthographic neighborhood size effects (Sears, Hino, \& Lupker, 1999).

Thus, there are two competing hypotheses regarding the source of orthographic $N$ effects. The orthographic neighborhood hypothesis states that facilitation from orthographic $N$ results from purely orthographic facilitation of word identification. The phonographic-orthographic or phonographic neighborhood hypothesis (cf. Peereman \& Content, 1997) states that facilitation from orthographic neighborhood size occurs because phonology that is consistent with the desired phonology is activated by most of the orthographic neighbors and is thus not purely orthographic.

Despite the widespread theoretical assumption that orthographic $N$ effects are due to print-sound conversion at the lexical level, there is almost no direct evidence to support the claim, especially in English. In regression analyses of their naming results on 92 French words, Peereman and Content (1995) divided the orthographic neighbors into those that were also phonological neighbors (i.e., could be generated from the word by replacing one phoneme) and those that were not, and they concluded that only those that were also phonologically similar contributed to the $N$ effect. However, the sample was small, and the regression did not control for known predictors of naming latencies aside from those relating to neighborhoods - including orthographic length, which correlates with neighborhood size. Peereman and Content argued specifically that the effects are due to lexical (whole word) rather than sublexical printsound conversion, since introducing pseudowords into the context, which should entail a strategic preference for (or focused attention upon) sublexical correspondences, decreases the $N$ effect. This effect does not, however, exclude a role for sublexical grapheme-phoneme correspondence rules, since it may reflect a shift in time criterion rather than route emphasis (see, e.g., Chateau \& Lupker, 2003).

The orthographic neighbors that are also phonological neighbors were termed phonographic neighbors by Peereman and Content (1997). For instance (in English), shove and stone are both orthographic neighbors of stove, but only stone is also its phonographic neighbor (since it is a phonological neighbor). Moreover, like stone, stoat is a phonological neighbor of stove, but it is not its phonographic neighbor (since it is not an orthographic neighbor). Although Yates (2005) has found evidence for phonological neighborhood effects in naming, and Yates, Lawrence Locker, and Simpson (2004) have suggested that some orthographic neighborhood effects might be due to phonological neighborhood, no evidence has been adduced for the latter point beyond the existence of the confound between the variables. Phonographic neighbors (rather than simply phonological neighbors) are of concern in the present article, since it is these that should be the cause of neighborhood effects, according to the phonographic neighborhood hypothesis.

Peereman and Content (1997) analyzed these phonographic neighbors by comparing naming latencies for French pseudowords that varied in phonographic neighborhood size, controlling orthographic neighborhood size (having shown that phonological neighborhood size has no effect). Despite this control on orthographic $N$, there was a facilitatory effect of phonographic $N$. However, they did not seek an orthographic neighborhood effect with phonographic neighborhood size controlled. From further experiments, they concluded that the effect was isolated to those neighbors whose difference was in the onset of the word. ${ }^{1}$ In effect, this conclusion meant that they were manipulating the number of friends (i.e., words that share both orthographic and phonological vowel and coda, although complex onsets mean that friends need not be phonographic neighbors). They also showed a facilitatory effect of friends for French words, replicating the result in English of Kay and Bishop (1987) and Brown (1987). Their conclusion that rimes are critical is surprising, given that their regression on their previous experiment with French words (Peereman \& Content, 1995) showed no unique effect for these. Moreover, their experiments did not rule out an effect of other kinds of neighbors for words. It is not clear that effects for pseudowords, which do not have a stored phonological representation, will necessarily generalize to words.

Currently, from mega-study data regarding English words, there is no evidence that higher level segmental spellingsound correspondences - that is, consistencies - are the cause of orthographic neighborhood effects in naming. Balota, Cortese, Sergent-Marshall, Spieler, and Yap (2004) entered both feed-forward and feed-backward consistency variables based on orthographic segments (onset, rime) into their analyses, but continued to find orthographic neighborhood effects. According to the phonographic neighborhood hypothesis, this result might not indicate that apparent orthographic neighborhood effects are due to something other than lexical spelling-sound correspondences, but that these kinds of measurement of lexical spelling-sound correspondence are too fine (are defined by similarities over too small a portion of the word). A further competing alternative is that the correspondences represented in these consistency variables are too coarse, and it is grapheme-phoneme correspondences that drive orthographic $N$ effects.

The availability of mega-study data is crucial in situations such as this, where predictors are difficult to manipulate factorially. Attempts to manipulate similar variables whilst controlling others result in small sets of stimuli (cf. Cutler, 1981) with insufficient power to detect effects. This is the case when comparing orthographic neighborhood size and phonographic neighborhood size; matched pairs of stimuli that do not differ on other spelling-sound measures are few in English. With large sets of data containing many words, variables that are not of interest can be covaried out of the analyses and power increased by the use of many items that would otherwise have to be ignored.

The orthographic and phonographic hypotheses regarding neighborhood facilitation in English word naming were therefore tested in the present work using word naming 
Table 1

Summary Statistics for Predictor and Response Variables in the Regression Analyses

\begin{tabular}{lrl}
\hline \multicolumn{1}{c}{ Variable } & \multicolumn{1}{c}{$M$} & \multicolumn{1}{c}{$S D$} \\
\hline Length & 4.360 & 0.864 \\
Log(frequency +1$)$ & 5.333 & 2.048 \\
Orthographic $N$ & 8.774 & 5.803 \\
Phonographic $N$ & 6.313 & 4.660 \\
Number of friends & 10.549 & 7.256 \\
Number of enemies & 1.375 & 3.015 \\
Consistency ratio & .883 & .216 \\
SB97 Young RT (msec) & 469.779 & 21.511 \\
BS98 Older RT (msec) & 661.622 & 37.867 \\
SW89 RT (msec) & 569.002 & 44.147 \\
Elexicon RT (msec) & 622.923 & 52.589 \\
\hline
\end{tabular}

Note-RT, response time.

data from four mega-studies. Since there could be effects of orthographic and phonographic neighbors from different sources, both phonographic and orthographic neighborhood size effects were sought. Finding a phonographic but not an orthographic neighborhood effect would confirm the phonographic neighborhood hypothesis, indicating that the word-letter feedback invoked by Andrews (1989) does not account for neighborhood effects.

\section{METHOD}

\section{Analyses}

To assess the extent to which orthographic and phonographic neighbors affect word naming, we conducted regression analyses that assess the unique influence of each variable when it is entered last (this is equivalent to simultaneous regression).

Predictors. Predictors in the regression analyses were (where necessary and not otherwise specified, from CELEX; Baayen, Piepenbrock, \& Gulikers, 1995)

$\log$ of frequency plus one;

orthographic neighborhood size;

phonographic neighborhood size - that is, the count of orthographic neighbors whose phonology could be formed by changing at most one phoneme;

first phoneme, as a (dummy coded) factor with 38 levels (no attempt was made to code phonetic features);

length (in letters);

exception cost by position of irregularity following the DRC model (Coltheart et al., 2001) as a (dummy coded) factor with six levels (regular, and five positions of irregularity); number of friends (words that look as though they rhyme, and do); number of enemies (words that look as though they rhyme, and do not); and types rime consistency ratio (i.e., friends divided by [friends plus enemies]).

Any effect of Body $N$, which is defined as the sum of number of friends and number of enemies, would be subsumed by the joint effects of number of friends and number of enemies in this type of analysis.

Summary statistics for the predictors (and response time [RT] measures described later) are in Table 1. Correlations are presented in Table 2. Orthographic $N$ correlates highly with phonographic $N$, but only $630(23.1 \%)$ of the words had identical orthographic and phonographic $N \mathrm{~s}$. The high correlation causes only higher error in estimates, not bias, and does not modify the probability of a Type I error. The negative effects on power that can result are mitigated by the large sample sizes in the analyses we report in this article.

RTs. Item mean RTs were taken from the data of Spieler and Balota (1997; SB97) and Balota and Spieler (1998; BS98) for 2,729 monosyllabic words (those with all the variables above) in the training set of the Plaut et al. (1996) model. Mean response times for the same words were also extracted when available from the data of Seidenberg and Waters (1989; SW89) (2,693 words) and Elexicon (Balota et al., 2000; Balota et al., in press; 2,667 words). Summary statistics are presented in Table 1.

\section{RESULTS}

Raw correlations are presented in Table 2. Table 3 shows the results of the regression analyses. There is a significant unique facilitatory effect of phonographic $N$, but not of orthographic $N$, across all four sets of data. The only evidence for an effect of orthographic $N$ was for an inhibitory effect in the SW89 data. Given the evidence that suggests an interaction between frequency and $N$, we conducted analyses that tested for orthographic $N$ effects by testing the improvement in $R^{2}$ from entering orthographic $N$ and its interaction with $\log$ frequency simultaneously as a block and phonographic $N$ effects with an analagous phonographic $N$ block. For all four data sets, the phonographic $N$ block had a significant effect after orthographic $N$ and its interaction with $\log$ frequency $[F(2, *)>6, p<.05]$, and the orthographic $N$ block did not have such an effect $[F(2, *)<2.1, p>.12]$.

\section{DISCUSSION}

In regression analyses on four sets of data, a facilitatory effect of phonographic $N$ was observed in English, concurring with Peereman and Content's (1995) regression on their experiment with French words and their later (Peereman \& Content, 1997) experiments with nonwords.

Table 2

Correlations Among Predictors and Between Predictors and Naming Latencies

\begin{tabular}{lrrrrrrr}
\hline & 1 & 2 & 3 & 4 & 5 & 6 & 7 \\
\hline 1. Length & - & & & & & & \\
2. Log(frequency + 1) & -.108 & - & & & & & \\
3. Orthographic $N$ & -.658 & .116 & - & & & & \\
4. Phonographic $N$ & -.580 & .056 & .895 & - & & & \\
5. Friends & -.281 & -.002 & .474 & .539 & - & & \\
6. Enemies & -.048 & .152 & .114 & -.111 & -.137 & - & \\
7. Consistency ratio & -.033 & -.153 & -.009 & .220 & .351 & -.820 & - \\
SB97 RT & .378 & -.301 & -.369 & -.353 & -.116 & -.001 & -.042 \\
BS98 RT & .325 & -.384 & -.303 & -.288 & -.125 & -.003 & -.042 \\
SW89 RT & .336 & -.215 & -.301 & -.321 & -.073 & -.005 & -.038 \\
Elexicon RT & .371 & -.343 & -.333 & -.331 & -.091 & -.001 & -.027 \\
\hline
\end{tabular}

Note-Predictor correlations are based on all 2,720 words that were analyzed from the SB97 and BS98 databases. RT, response time. 
Moreover, this effect occurred in the absence of any additional facilitation from other orthographic neighbors. This reliance on consistency between similar orthography and similar phonology implicates print-sound conversion processes. Moreover, this effect appeared to be over and above those of regularity and rime consistency, since these were partialed out in the analyses.

These results contradict the orthographic neighborhood hypothesis that neighborhood effects result from interactions at purely orthographic levels. By contrast, the results are as would be expected from a number of models of visual word recognition. The primary constraint arising is that generalization of print-sound correspondence can be influenced by individual words. This arises in IA models (see, e.g., McClelland \& Rumelhart, 1981) and the IAbased portion of the DRC (Coltheart et al., 2001), as a consequence of the error arising from individual words in backpropagation PDP models (e.g., Plaut et al., 1996; Seidenberg \& McClelland, 1989; Zorzi et al., 1998), and from the retrieval of individual words in memory-based models (e.g., Kwantes \& Mewhort, 1999).

Because it appears that orthographic neighbors of a word aid its naming only insofar as they closely support the correct pronunciation of this word (by being phonological and, hence, phonographic neighbors), it is perhaps surprising that there is little or no inhibitory effect of orthographic $N$ once phonographic $N$ is controlled. Such inhibition might be expected because the additional orthographic neighbors support incorrect pronunciations of the target word; if phonographic neighbors are activated on the basis of the orthographic input, so should all other orthographic neighbors. The lack of an inhibitory effect may occur because most of the orthographic neighbors that are not phonological neighbors only differ in two phonemes whose pronunciation they hinder, but give the correct pronunciation for the remainder that they help; this may be almost the correct balance to be equivalent to no neighbor at all. Within this explanation, confusion arising from high neighborhood density, which ordinarily would slow identification per se (cf. Snodgrass \& Mintzer, 1993), speeds naming. Alternatively, there may be no competitive inhibition between phonemes or words in normal reading, as was the case in the model of Brown (1987).

Since there is no evidence for an orthographic neighborhood size effect per se, no feedback from word to letter recognition is necessary to account for neighborhood size effects. Moreover, models that lack this kind of feedback, but assume that responses in letter identification can be augmented by word identification in a feedforward manner (see, e.g., Paap, Newsome, McDonald, \& Schvaneveldt, 1982), can predict word-superiority in the Reicher-Wheeler task. If such word identification occurs independently, we would have neighborhood size facilitation of pronunciation without such facilitation of identification. Indeed, one would expect neighborhood effects to occur in processing before full identification is possible - that is, where confusion is possible or likely.

It has been shown that in word naming, neighborhood size effects should be considered in terms of phonographic rather than orthographic neighbors. As such, print-sound

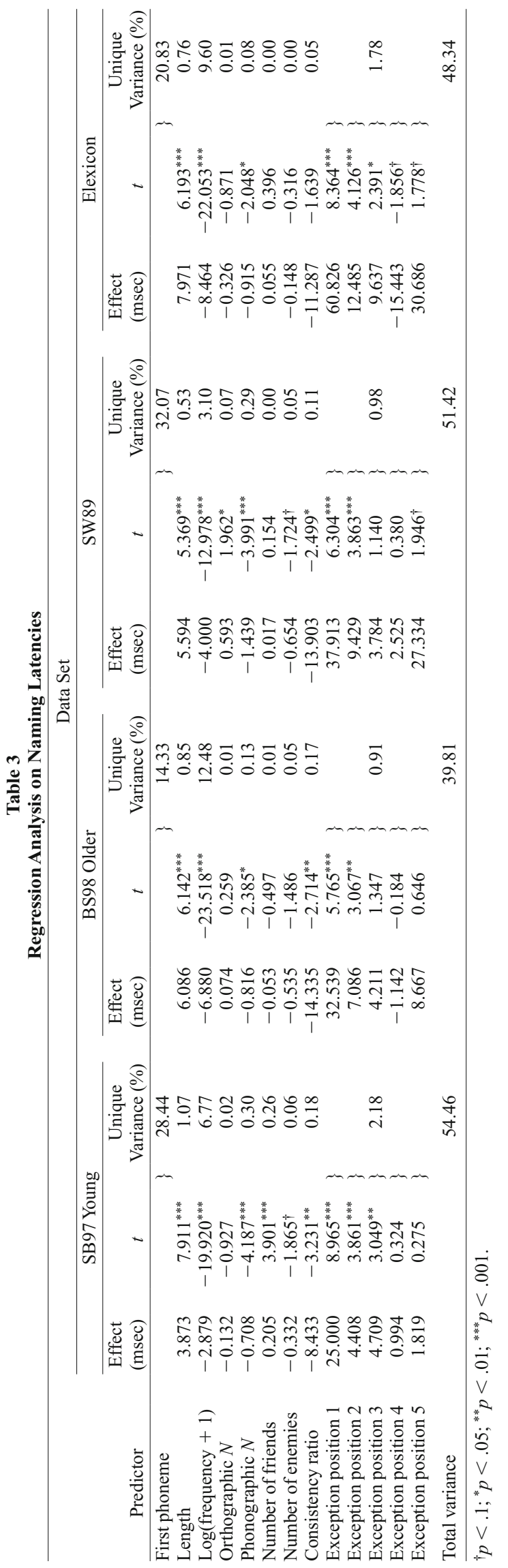


consistency and, hence, print-sound conversion are implicated as the source of these effects rather than orthographic feedback. Such conversion could be based on the result of orthographically similar words competing for identification and influencing pronunciation before correct identification is complete.

\section{AUTHOR NOTE}

This work was supported by a Warwick Postgraduate Research Fellowship awarded to J.S.A. and by grants F/215/AY from the Leverhulme Trust and RES 000221558 from the ESRC. We thank Marjolein Merkx for helpful comments on an earlier version of this article. Address correspondence to J. S. Adelman, Department of Psychology, University of Warwick, Gibbet Hill Road, Coventry CV4 7AL, England (e-mail: j.s.adelman@warwick.ac.uk).

\section{Note-Accepted by David A. Balota's editorial team.}

\section{REFERENCES}

ANDREws, S. (1989). Frequency and neighborhood effects on lexical access: Activation or search? Journal of Experimental Psychology: Learning, Memory, \& Cognition, 15, 802-814.

ANDREwS, S. (1992). Frequency and neighborhood effects on lexical access: Lexical similarity or orthographic redundancy? Journal of Experimental Psychology: Learning, Memory, \& Cognition, 18, 234-254.

ANDREws, S. (1997). The effect of orthographic similarity on lexical retrieval: Resolving neighborhood conflicts. Psychonomic Bulletin \& Review, 4, 439-461.

BaAyen, R. H., Piepenbrock, R., \& Gulikers, L. (1995). The CELEX Lexical Database (Release 2) [CD-ROM]. Philadelphia: Linguistic Data Consortium, University of Pennsylvania.

Balota, D. A., Cortese, M. J., Hutchison, K. A., Neely, J. H., Nelson, D., Simpson, G. B., ET AL. (2000). The English Lexicon Project: A Web-based repository of descriptive and behavioral measures for 40,481 English words and nonwords. Retrieved December 11, 2004, from http://elexicon.wustl.edu.

Balota, D. A., Cortese, M. J., Sergent-Marshall, S. D., Spieler, D. H., \& YAP, M. J. (2004). Visual word recognition of single-syllable words. Journal of Experimental Psychology: General, 133, 283-316.

Balota, D. A., \& Spieler, D. H. (1998). The utility of item-level analyses in model evaluation: A reply to Seidenberg and Plaut. Psychological Science, 9, 238-240.

Balota, D. A., Yap, M. J., Cortese, M. J., Hutchison, K. I., Kessler, B., Loftis, B., ET AL. (in press). The English Lexicon Project. Behavior Research Methods.

Brown, G. D. A. (1987). Resolving inconsistency: A computational model of word naming. Journal of Memory \& Language, 26, 1-23.

Chateau, D., \& LuPKer, S. J. (2003). Strategic effects in word naming: Examining the route-emphasis and time-criterion accounts. Journal of Experimental Psychology: Human Perception \& Performance, 29, 139-151.

Coltheart, M., Davelaar, E., Jonasson, J. T., \& Besner, D. (1977). Access to the internal lexicon. In S. Dornic (Ed.), Attention and performance VI (pp. 535-555). Hillsdale, NJ: Erlbaum.

Coltheart, M., Rastle, K., Perry, C., Langdon, R., \& Ziegler, J. (2001). DRC: A dual route cascaded model of visual word recognition and reading aloud. Psychological Review, 108, 204-256.

CUTLER, A. (1981). Making up materials is a confounded nuisance, or: Will we be able to run any psycholinguistic experiments at all in 1990 ? Cognition, 10, 65-70.

JaCoBs, A. M., \& Grainger, J. (1992). Testing a semistochastic variant of the interactive activation model in different word recognition experiments. Journal of Experimental Psychology: Human Perception \& Performance, 18, 1174-1188.

KAY, J., \& Bishop, D. (1987). Anatomical differences between nose, palm, and foot, or, the body in question: Further dissection of the processes of sub-lexical spelling-sound translation. In M. Coltheart (Ed.), Attention and performance XII: The psychology of reading (pp. 449469). Hillsdale, NJ: Erlbaum.

Kwantes, P., \& Mewhort, D. J. (1999). Modeling lexical decision and word naming as a retrieval process. Canadian Journal of Experimental Psychology, 53, 306-315.

Mathey, S. (2001). L'influence du voisinage orthographique lors de la reconnaisance des mots écrits [The influence of orthographic neighborhood on visual word recognition]. Revue Canadienne de Psychologie Expérimentale/Canadian Journal of Experimental Psychology, 55, 1-23.

McClelland, J. L., \& Rumelhart, D. E. (1981). An interactive activation model of context effects in letter perception: Part 1. An account of basic findings. Psychological Review, 88, 375-407.

Paap, K. R., Newsome, S. L., McDonald, J. E., \& Schvaneveldt, R. W. (1982). An activation-verification model for letter and word recognition: The word-superiority effect. Psychological Review, 89, 573-594.

Peereman, R., \& Content, A. (1995). Neighborhood size effect in naming: Lexical activation or sublexical correspondences? Journal of Experimental Psychology: Learning, Memory, \& Cognition, 21, 409-421.

Peereman, R., \& Content, A. (1997). Orthographic and phonological neighborhoods in naming: Not all neighbors are equally influential in orthographic space. Journal of Memory \& Language, 37, 382-410.

Plaut, D. C., McClelland, J. L., Seidenberg, M. S., \& Patterson, K. (1996). Understanding normal and impaired reading: Computational principles in quasi-regular domains. Psychological Review, 103, 56-115.

Reicher, G. M. (1969). Perceptual recognition as a function of meaningfulness of stimulus material. Journal of Experimental Psychology, 81, 275-280.

REYNOLDS, M., \& BESNER, D. (2002). Neighbourhood density effects in reading aloud: New insights from simulations with the DRC model. Canadian Journal of Experimental Psychology, 56, 310-318.

Sears, C. R., Hino, Y., \& LupKer, S. J. (1999). Orthographic neighbourhood effects in parallel distributed processing models. Canadian Journal of Experimental Psychology, 53, 220-229.

SeidenberG, M. S., \& McClelland, J. L. (1989). A distributed, developmental model of word recognition and naming. Psychological Review, 96, 523-568.

SeidenberG, M. S., \& Waters, G. S. (1989). Word recognition and naming: A mega study. Bulletin of the Psychonomic Society, 27, 489.

SNODGRASS, J. G., \& MinTZER, M. (1993). Neighborhood effects in visual word recognition: Facilitatory or inhibitory? Memory \& Cognition, 21, 247-266.

Spieler, D. H., \& Balota, D. A. (1997). Bringing computational models of word naming down to the item level. Psychological Science, $\mathbf{8}$, 411-416.

Wheeler, D. D. (1970). Processes in word recognition. Cognitive Psychology, 1, 59-85.

Yates, M. (2005). Phonological neighbors speed visual word processing: Evidence from multiple tasks. Journal of Experimental Psychology: Learning, Memory, \& Cognition, 31, 1385-1397.

Yates, M., Lawrence Locker, J., \& Simpson, G. B. (2004). The influence of phonological neighborhood on visual word perception. Psychonomic Bulletin \& Review, 11, 452-457.

Ziegler, J., Perry, C., Jacobs, A., \& Braun, M. (2001). Identical words are read differently in different languages. Psychological Science, 12, 379-384.

Zorzi, M., Houghton, G., \& Butterworth, B. (1998). Two routes or one in reading aloud? A connectionist dual-route model. Journal of Experimental Psychology: Human Perception \& Performance, 24, 1131-1161

\section{NOTE}

1. Peereman and Content (1997) termed the phonographic neighbors that differ in the onset body neighbors and considered only those that had simple onsets. Other authors (e.g., Ziegler, Perry, Jacobs, \& Braun, 2001) have used "body $N$ " to refer to the number of words that have the same orthographic rime, and we follow the latter, more common, usage later in the article, although this is inconsistent with the usual idea of a neighbor different in only one unit.

(Manuscript received March 9, 2004; revision accepted for publication August 9, 2006.) 